\title{
BIOLOGIC AND PROSTHETIC COMPLICATIONS WITH ACRYLIC AND PORCELAIN FIXED HYBRID PROSTHESIS USED FOR REHABILITATION OF EDENTULOUS MANDIBLE ACCORDING TO THE "ALL ON FOUR" IMPLANT CONCEPT. A 3 YEAR PROSPECTIVE STUDY
}

\author{
Nasser Hussein Shaheen* and Samer Mostafa Ali **
}

\begin{abstract}
Purpose: The aim of this study was to evaluate biologic and prosthetic complications with acrylic and porcelain fixed hybrid prosthesis used for rehabilitation of edentulous mandible according to the "All on four" concept.

Materials and methods: Ten edentulous patients received new maxillary and mandibular dentures. Four implants were inserted in the inter-foraminal area of the mandibular jaw according to the "All on four concept" and the implants were immediately loaded with lower denture. After 3 months, the patients were randomly assigned into two equal groups: Group I: received fixed ceramometal prosthesis (PFM), Group II; received metal acrylic hybrid prosthesis (MAP). Biological and prosthetic complications were measured for provisional dentures after 3 months of loading and for definitive prosthesis after 3 year.
\end{abstract}

Results: The most common biological complication was increased pocket depth and bone loss which was significantly higher for PFM compared to MAP. Regarding provisional denture, the most common complication was denture fracture and prosthetic screw loosening. The most common complication for definitive prosthesis was crown fracture, teeth wear and prosthetic screw loosening. Crown fracture and teeth wear were higher in MAP and abutment screw loosening was higher in PFM.

Conclusion: Within the limitation of the current study PFM and MAP could be used successfully for All on four implant rehabilitation of edentulous mandible. However, MAP may be advantageous than PFM regarding biologic complications (increased pocket depth and marginal bon loss) and abutment screw loosening. On the other hand, PFM may be preferred than MAP in terms of crown fracture and teeth wear/replacement.

* Associate Professor, Department of Removable Prosthodontics, College of Oral and Dental Surgery, Misr University for Science and Technology, Egypt.

**Associate Professor, Department of Removable Prosthodontics, Faculty of Dentistry, Modern Science and Arts University (MSA), Egypt 


\section{INTRODUCTION}

The rehabilitation of severely atrophic mandible using implant-supported prosthesis is often challenging because of the poor quality and quantity of residual jawbone. Most patients wearing complete dentures had problem related to stability of their dentures, with difficulty in mastication, and require a fixed prosthetic solution. ${ }^{(1)}$. Completely edentulous mandible can be managed by several implant treatment options, such as implant overdentures, fixed porcelain fused to metal implant supported prosthesis, or fixed implant supported hybrid prosthesis $^{(2)}$.

The concept of the all-on-fouris toinsert 4 implants in the anterior part of the ridge to assist a temporary, fixed, and immediately loaded bridge. The anterior 2 implants are installed vertically, and the posterior 2 fixtures are inserted with distal inclination to decrease the cantilever length and permit the use of prosthesis with 10 to 12 teeth ${ }^{(3,4)}$. Final prosthesis may be fixed or hybrid screw retained prosthesis ${ }^{(5)}$. With All-on-Four treatment, bone augmentation and inferior alveolar nerve displacement are omitted. Furthermore, restoration support is improved due to increasing the anteroposterior spread and shortening of cantilevers which provide optimum load sharing. Additionally, the grafting procedures may be omitted, causing reduced morbidity and costs. Moreover, the immediate function concept represents a major advantage for patients, providing less time-consuming treatments ${ }^{(6,7)}$. Several types of final prosthesis were reported to be used with the All on four implant concepts. They include metal ceramic or metal acrylic permanent prosthesis, or final prosthesis remained in acrylic resin ${ }^{(8,9)}$.

The conventional final prosthesis used for Allon-four implant rehabilitation is the fixed metal ceramic prosthesis. A metal-acrylic fixed restoration is indicated with moderate-to-severe bone loss, to restore the lip and cheek support, with its acrylic resin base ${ }^{(10)}$. Zarb and Jansson reported that fixed restoration could be made either with metal frameworks which form the main component of the prosthesis, acrylic teeth and part of denture bases or prosthesis formed mainly of acrylic resin denture bases and acrylic teeth, with reduced size metal frameworks. ${ }^{(11)}$

Although the "All-on-four concept" showed a favorable clinical outcomes in the last 2 decades ${ }^{(3,9,12-}$ ${ }^{14)}$, these findings should be approached with caution due to lack of long-term outcome on the prosthetic and biologic complications and their management ${ }^{(10)}$. Implant success and survival is not only the key of success of a specific type of rehabilitation, but also biological and prosthetic complications play an important role ${ }^{(15)}$. It is essential for prosthodontists to recognize the long-term performance of specific prosthesis to achieve increased patient satisfaction and oral heath related quality of life.

Reviewing the literature, there is a lack of long-term reports about the incidence of potential prosthetic and biologic complications and their implications with metal acrylic fixed prosthesis used for All-on-four implant concept. Therefore, the aim of the present study was to evaluate biologic and prosthetic complications with acrylic and porcelain fixed hybrid prosthesis used for rehabilitation of edentulous mandible according to the "All-on-four" implant concept. The null hypothesis was that there will be no significant difference in biologic and prosthetic complications between the 2 types of tested prosthesis.

\section{MATERIALS AND METHODS}

\section{Patient selection and study design}

Ten (5 males and 5 females) completely edentulous patients (age between 50-64 years) were selected according to the following criteria: 1) All patients complained from insufficient retention and 
stability of their mandibular conventional dentures due to atrophic ridges, 2) Patients presented clear preference for a fixed implant-supported rehabilitation, 3) Sufficient bone quantity (class IVVI) according to Cawood and Howell ${ }^{(16)}$ and quality (verified cone beam computerized tomography) in the interforaminal area of the mandible to receive standard implants of at least $11 \mathrm{~mm}$ length and 3.75 $\mathrm{mm}$ in diameter, 4) Sufficient restorative space of at least $15 \mathrm{~mm}$ to accommodate both types of tested prosthesis. This was detected by tentative jaw relation. Study casts with all anatomic landmarks were obtained from well-extended impressions of the patients' jaws and mounted on articulators using a face bow transfer and accurate interocclusal records, and 5) Last extraction not less than one year. Exclusion criteria include: 1) General contraindications for surgical procedures such as patients with head and neck radio therapy, patients with bleeding disorders, hepatic patients, 2) Patients with metabolic disorders that affect osseointegration such as diabetes mellitus, and osteoporosis, 3) Long term immunosuppressive and corticosteroid drug therapy and smoking patient. After the patients were informed about the line of treatment and the need for regular and frequent recalls, they all signed a written consent. The study was conducted according to the ethical principles stated and approved by the ethical committee of the faculty of dentistry, Misr University for Science and Technology (MUST).

All selected patients received new maxillary and mandibular dentures (CD). After 1-month adaptation period, all patients received 4 implants in the interforaminal area of the mandibular jaw according to the "All on four concept" and the implants were immediately loaded with lower denture. After 3 months of healing, the patients were randomly assigned into 2 groups: 1) Group I: include 5 patients who received Fixed ceramometal (porcelain fused to metal) hybrid screw retained prosthesis (PFM), 1) Group II; include 5 patients who received metal acrylic hybrid screw retained prosthesis (MAP). The randomization was done to ensure equal gender distribution in groups using random numbers generated in Excel spread sheet.

\section{Surgical and prosthetic procedures}

Radiopaque gutta-perchae markers are added to the polished surface of the mandibular denture at labial, buccal and lingual flanges. Dual scan protocol was followed using cone beam CT (CBCT, i-CAT, Imaging Sciences International ISI, Pennsylvania, USA), Firstly, the patients were scanned while wearing their mandibular dentures, then the mandibular dentures were scanned alone. The two data sets of the double scans were overlapped then the acquired images were loaded into 3-D image treatment planning software (OnDemand). According to the CT scan, the implants were virtually planned according to the All On four protocol, then an individualized stereolithographic surgical guide was constructed using prototyping technique. The four implants were placed virtually in the optimizing position, angulation and distribution. Anterior implants were placed at canine/ lateral incisor area parallel to each other and perpendicular to occlusal plane. Distal fixtures were installed in premolar area anterior to mental foramina with safety margin from the foramina, posterior implants were tilted distally to form a 30-degree angle from the vertical plane and implants were emerged in the mesial cusp region of the first molar tooth. This arrangement allowed for good implant anchorage, short cantilever length, and large interimplant distance ${ }^{(3,17)}$. Virtual model planning software was used to define the sites for implant placement and anchor pins for the surgical guide. A mucosal supported stereolithographic surgical template (Fig: 1) with 4 sleeves positioned over proposed implant sites was constructed using 3D printing technology (In2Guide). 


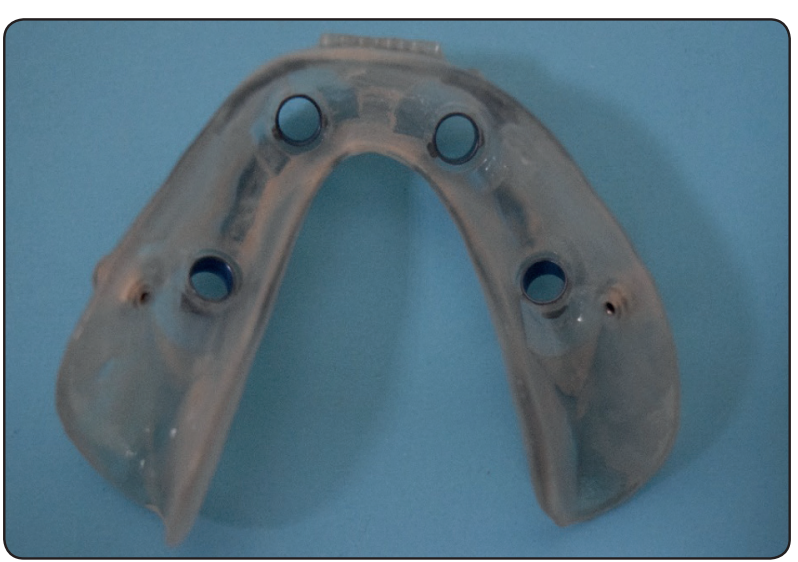

Fig. (1): Mucosal supported stereolithographic guide

All patients were sedated with diazepam before operation. Antibiotics (amoxicillin 625mg + clavulanic acid 125mg, Augmentin ${ }^{\circledR} 1 \mathrm{gm}$ ) were prescribed before surgery and continued 6 days later. Corticosteroids (Dexamethazone ${ }^{\circledR}$ ) was given. Anti-inflammatory medication (ibuprofen ${ }^{\circledR}$, $600 \mathrm{mg}$ ) was administered for 4 days postoperatively. Analgesics (Ketolac ${ }^{\circledR} 10 \mathrm{mg}$ ) were given on the day of surgery and postoperatively for the first 4 days. Local anesthesia was administered. Four implants (TioLogic, Dentaurum, Germany) were inserted according the flapless surgical protocol using the surgical guide and the universal surgical kit (In2Guide, Universal Kit Cybermed Inc) supplied with the mucosal supported stereolithographic surgical template to be used during osteotomy preparation (Fig: 2). This kit includes hand drill sleeves with successive increasing diameters that fit the template sleeves. The hand sleeves were used during consecutive drilling procedures with surgical guide to accommodate successive increasing in drill diameter. The template was stabilized in the patient's mouth by a rubber base interocclusal record and fixed to the mandibular bone using anchor pins. The minimum torque at implant placement was $35 \mathrm{Ncm}$ to permit immediate loading of the implants ${ }^{(18)}$.

Straight multiunit abutments (AngleFix abutments) were screwed to the canine implants and 30-degree multiunit abutment were screwed

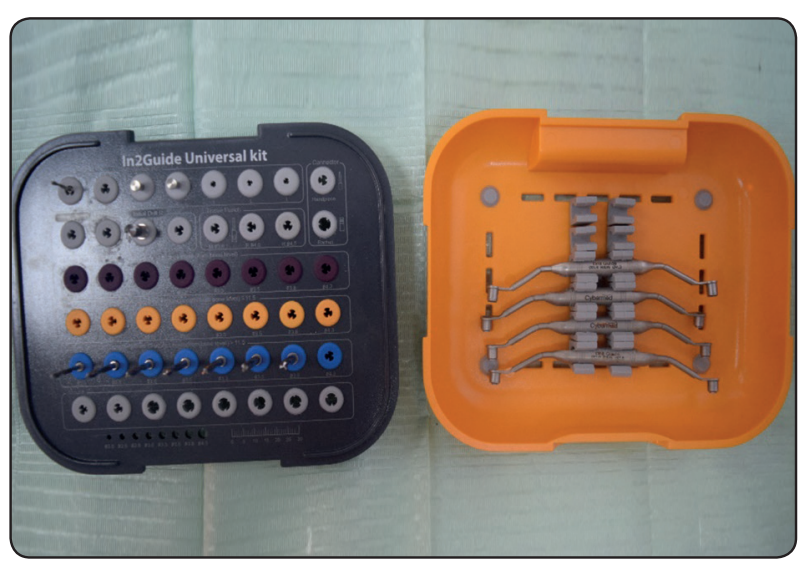

Fig. (2): In2Guide surgical kit

to premolar implants at $20 \mathrm{Ncm}$ torque. Implants were immediately loaded by existing mandibular dentures. The denture was modified by removal of the labial and buccal flanges and the second molar artificial teeth ${ }^{(19)}$. Temporary metal caps were screwed to the multiunit abutments. The denture base opposite to the multiunit abutments was hollowed. Rubber dam sheet was fastened to the abutments. The temporary metal caps were picked up to the modified denture using auto polymerized acrylic resin (Fig. 3). The occlusal contact of first molar with opposing denture was removed to relieve the pressure on the inclined posterior implants. Postoperative medications include analgesics to relieve pain, systemic antibiotic cover (amoxicillin and clavulanic acid (Augmentin ${ }^{\circledR} 1 \mathrm{gm}$ ) for 17 days, a chlorhexidine digluconate $0.2 \%$ mouth rinse for 2 weeks and direct application of anti-inflammatory gel to the peri-implant area. Anti-inflammatory medication was prescribed post surgically from days 5 to 10. Participants were informed to eat soft diet and avoid hard foods. Participants were instructed for oral hygiene procedures and informed to attend regular follow-up visits to verify oral hygiene practice and perform adjustments of the relined dentures till osseointegration occurs.

After 3 months of osseointegration period, open tray impression procedure was started. The provisional acrylic denture was un-screwed from 


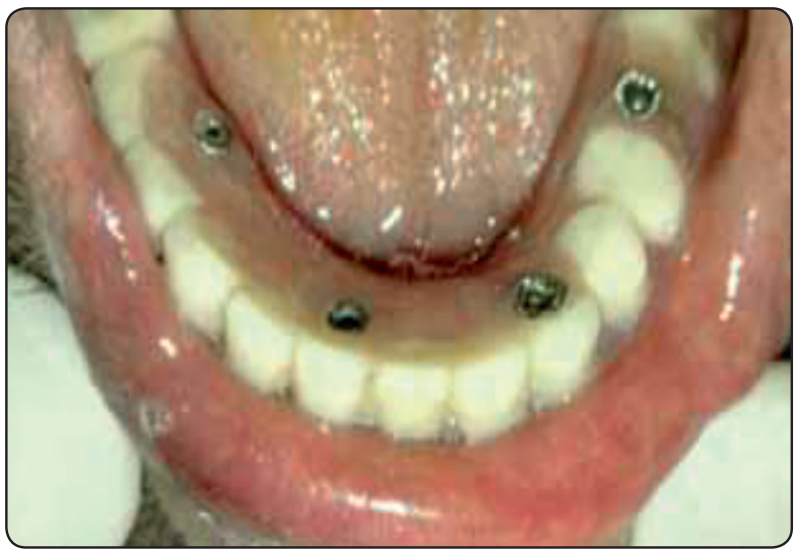

Fig. (3): Immediate loading of the implants by provisional denture

the multi-unit abutments. The abutment level long transfer copings were screwed to the multi-unit abutment and splinted with orthodontic ligature wire and light cure flowable composite resin to prevent movement of the transfer coping during impression procedure. A special tray was perforated over the transfer coping to allow unscrewing of the transfer after impression making. Light body rubber base impression (Zhermack®, Badia Polesine, Rovigo, Italy) was injected around the transfer coping. The tray was filled with heavy body impression material and seated so that the tips of all the guide pins are identified. The long transfer copings were unthreaded and the impression was removed from patient mouth. Abutment analogues were screwed to the transfer coping and the impression was poured to obtain master cast. Plastic caps were screwed to the abutment analogues on the master cast.

For Group I (PFM), the cast was scanned using a CAD/CAM device (Ceramill Map400, Amann Girrbach AG. Koblach, Austria), then a cast metalceramic fixed prosthesis that replace lost gingival tissues with pink porcelain was planned using the software of the device. The fixed partial denture was milled in polymerized resin discs (Duralay, Reliance Dental MFG Co, Worth, IL, USA) and tried in patient mouth for passive fit. The resin pattern was cast in a nonprecious cobalt-chromium alloy (Heraenium Pw, Heraeus-Kulzer GmbH,

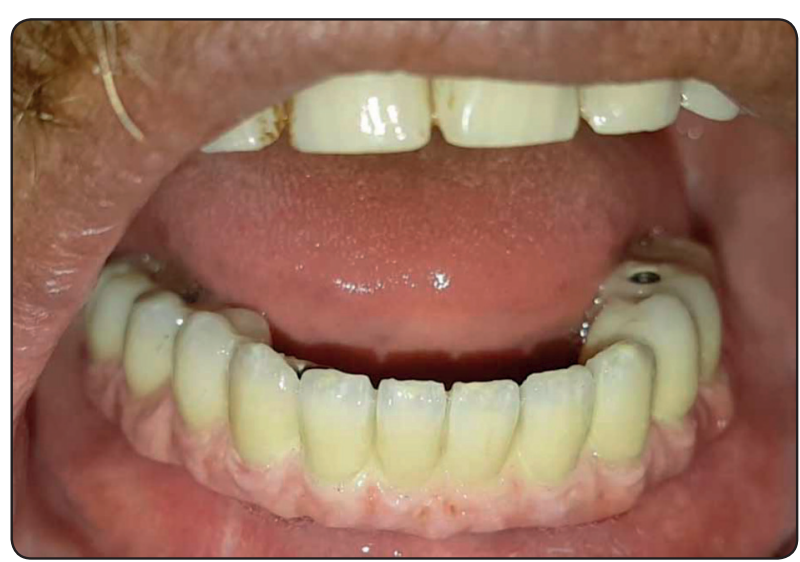

Fig. (4): Porcelain fused to metal fixed prosthesis (PFM)

Hanau, Germany). The cast superstructure was tried intraorally for passivity using the single screw Sheffield test. The porcelain powder was mixed with the modeling liquid, applied onto the cobaltchromium metal substructure over the opaque layer, fired, finished and glazed (fig 4).

For group II (MAP), the prosthesis composed of CAD/CAM-fabricated cobalt chromium (Co$\mathrm{Cr}$ ) framework covered by acrylic resin teeth and pink acrylic resin that replace lost bone and gingival tissues. After scanning the cast, the metal framework was designed using the CAD/CAM device software to give proper thickness for rigidity, and access for oral hygiene $(1 \mathrm{~mm}$ space under the frame for cleaning purposes), reduced metal show, and adequate thinning of frameworks to permit good attachment of acrylic teeth and denture bases. Similarly, the framework was milled in polymerized resin discs (Duralay, Reliance Dental MFG Co, Worth, IL, USA) and tried in patient mouth for passive fit, then invested, and casted with a nonprecious cobalt-chromium alloy (Heraenium Pw, Heraeus-Kulzer GmbH, Hanau, Germany). The cast superstructure was tried intraorally for passivity using the single screw Sheffield test. Artificial teeth of the same size and shade of the provisional denture were arranged over the framework and waxing up was completed. Intraoral try-in on the framework (framework with wax/denture teeth) was made to 
evaluate occlusion and esthetics. After flasking, the prosthesis was processed into heat cure acrylic resin, finished and polished (Fig. 5). For both groups, the screw retained prosthesis has 12-unit artificial teeth in both groups with one artificial tooth as maximum cantilever of. In this final prosthesis, the occlusion mimicked natural dentition ${ }^{(9)}$. The final prosthesis was delivered typically 3 months postsurgically. The screws access holes were sealed with composite $\operatorname{resin}^{(18)}$.

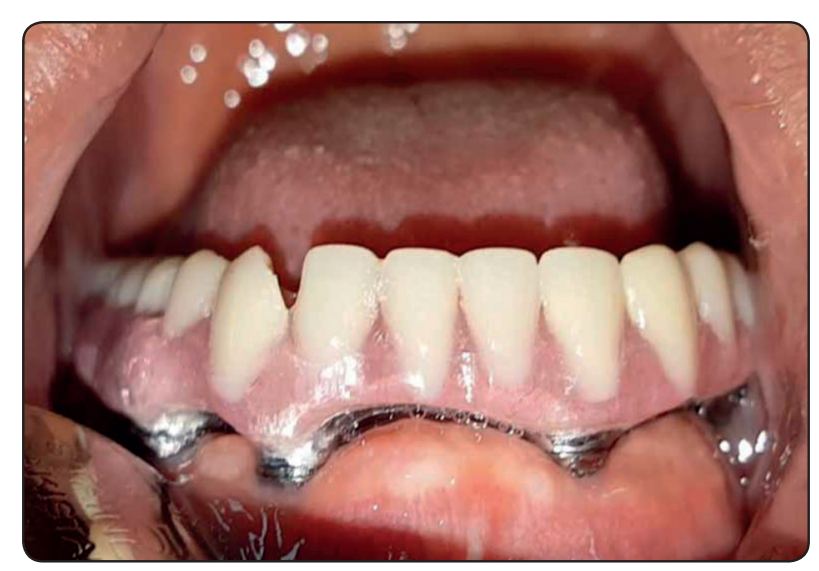

Fig. (5): Metal acrylic fixed prosthesis (MAP)

\section{Evaluation of biologic and prosthetic complications}

The following biological complications (on the implant level) were measured ${ }^{(15)}$ : Implant loss, implant survival and success, Pain, swelling abscess, fistulae formation, peri-implantitis , per-implant mucositis, mucosal bleeding, pocket depths $>5 \mathrm{~mm}$, and vertical bone resorption $>2.5 \mathrm{~mm}$.

Prosthetic complications were measured for provisional prosthesis and final prosthesis (15). Provisional prosthesis complications include: Prosthesis fracture, Abutment fracture, Abutment screw loosening, Prosthetic screw fracture and Prosthetic screw loosening. Definitive prosthesis complications include Prosthesis fracture, Ceramic crown fracture, Acrylic crown fracture, Cylinder fracture, artificial gingiva fracture, Abutment fracture, Abutment screw loosening, Prosthetic screw fracture, and Prosthetic screw loosening.

Both biological and prosthetic complications were measured after 3 months of loading for provisional dentures and after 3 year for definitive prosthesis insertion.

\section{Statistical analysis}

SPSS ${ }^{\circledR}$ software version 25 (SPSS Inc., Chicago, IL, USA) was used for data analysis. The complications were calculated on implant level. The descriptive statistics of both biologic and prosthetic complications for both groups were calculated in terms of frequency and percentages using frequency distribution (contingency) tables. To test the difference in proportions of biologic and prosthetic complications between groups, Chi square test was used. P-values $<0.05$ were considered to be significant.

\section{RESULTS}

The frequency distribution (incidence) and percentages of biologic complications of both groups are presented in table 1 . The most common complication was increased pocket depth and marginal bone loss which occurred frequently in the tilted posterior implants. One implant $(5 \%$, in one patient) failed in each group resulted in $95 \%$ implant survival rate in each group. The failed implants were the distal (inclined) implants on the left side of each patient and the failure occurred in the first 3 months after loading with provisional dentures. The failed implants were replaced by newer implants of increasing diameters (width and length) and left submerged to integrate without loading and they included in the support of the final prosthesis. The 2 implant failures were due to implant overload and they were mobile only and not associated with infection or suppuration. One implant in each group (5\%) was associated with pain and swelling. None of the implants were associated with abscess or fistula 
formation in both groups. Two implants in each group (10\%) were associated with peri-implantitis with increased peri-implant bone loss and mucosal inflammation but without mobility. The patients were submitted to periodontal therapy and not excluded from the study. Four patients $(20 \%)$ in each group were associated with peri-implant mucositis and bleeding on probing. Five implants $(25 \%)$ and one implant (5\%) in PFM and MAP respectively were associated with pocket depth $>5 \mathrm{~mm}$ and marginal bone $>2.5 \mathrm{~mm}$. There was a significant difference in pocket depth and marginal bone loss between groups. PFM was associated with significant higher pocket depth and marginal bon loss than MAP $(\mathrm{p}=.049)$. However, no difference between groups was noted for other biological complications.

The frequency distribution (incidence) and percentages of prosthetic (technical) complications of provisional and definitive prosthesis in both groups are presented in table 2. Regarding provisional denture, the most common complication was denture fracture and prosthetic screw loosening. Denture fracture occurred in 2 out of 5 prosthesis in each group (40\%). No fractures occur in abutment or prosthetic screws in both groups. The incidence of abutment screw loosening was 3 (15\%) in each group. The incidence of prosthetic screw loosening was $9(45 \%)$ in each group. No significant difference in prosthetic complications of provisional dentures was noted between groups.

With respect to definitive prosthesis, the most common complication was crown fracture and teeth wear in the MAP group. For both groups also prosthetic screw loosening was the second common complication. Prosthesis fracture, cylinder fracture and abutment fracture did not occur in both groups. The incidence of crown fracture was 1 (20\%) and 3 (60\%) for PFM and MAP respectively. The incidence of teeth wears and replacement was $0(0 \%)$ and 3 (60\%) for PFM and MAP respectively. The artificial gingival fracture was $1(20 \%)$ and $2(40 \%)$ for PFM and MAP respectively. Abutment screw loosening occurred in $5(25 \%)$ and $1(5 \%)$ in PFM and MAP respectively. The incidence of prosthetic screw fracture was $2(10 \%)$ in both groups. The incidence of prosthetic screw loosening was 3(15\%) in both groups. There was a significant difference between groups in crown fracture, teeth wear and abutment screw loosening. Crown fracture and teeth wear/ replacement were significantly higher in MAP than PFM. On the other hand, abutment screw loosening was significantly higher in PFM than MAP.

TABLE (1) Biological complications of both groups.

\begin{tabular}{|c|c|c|c|c|c|}
\hline & \multicolumn{2}{|c|}{ PFM } & \multicolumn{2}{|c|}{ MAP } & \multirow[t]{2}{*}{$P$ value } \\
\hline & Incidence & Percentage & Incidence & Percentage & \\
\hline Implant loss (failure) & 1 & $5 \%$ & 1 & $5 \%$ & 1.00 \\
\hline Implant survival and success & 19 & $95 \%$ & 19 & $95 \%$ & 1.00 \\
\hline Pain, swelling & 1 & $5 \%$ & 1 & $5 \%$ & 1.00 \\
\hline Abscess, fistulae formation & 0 & $0 \%$ & 0 & $0 \%$ & - \\
\hline Peri-implantitis & 2 & $10 \%$ & 2 & $10 \%$ & 1.00 \\
\hline Per-implant mucositis & 4 & $20 \%$ & 4 & $20 \%$ & 1.00 \\
\hline Bleeding on probing & 4 & $20 \%$ & 4 & $20 \%$ & 1.00 \\
\hline Peri-implant pockets $>5 \mathrm{~mm}$ & 5 & $25 \%$ & 1 & $5 \%$ & $.049 *$ \\
\hline Marginal bone loss $>2.5 \mathrm{~mm}$ & 5 & $25 \%$ & 1 & $5 \%$ & $.049 *$ \\
\hline
\end{tabular}


TABLE (2) Prosthetic complications of provisional and definitive prosthesis for both groups.

\begin{tabular}{|c|c|c|c|c|c|}
\hline & \multicolumn{2}{|c|}{$\begin{array}{l}\text { PFM } \\
\mathrm{N}=20\end{array}$} & \multicolumn{2}{|c|}{$\begin{array}{l}\text { MAP } \\
\mathrm{N}=\mathbf{2 0}\end{array}$} & \multirow[t]{2}{*}{ P value } \\
\hline & Incidence & Percentage & Incidence & Percentage & \\
\hline & \multicolumn{4}{|c|}{ Provisional denture } & \\
\hline Prosthesis fracture & 2 & $40 \%$ & 2 & $40 \%$ & 1.00 \\
\hline Abutment fracture & 0 & $0 \%$ & 0 & $0 \%$ & - \\
\hline Abutment screw loosening & 3 & $15 \%$ & 3 & $15 \%$ & 1.00 \\
\hline Prosthetic screw fracture & 0 & $0 \%$ & 0 & $0 \%$ & - \\
\hline \multirow[t]{2}{*}{ Prosthetic screw loosening } & 9 & $45 \%$ & 9 & $45 \%$ & 1.00 \\
\hline & \multicolumn{4}{|c|}{ Definitive prosthesis } & \\
\hline Prosthesis fracture & 0 & $0 \%$ & 0 & $0 \%$ & - \\
\hline Crown fracture & 1 & $20 \%$ & 3 & $60 \%$ & $.037 *$ \\
\hline Teeth wear and replacement & 0 & $0 \%$ & 3 & $60 \%$ & $.001 *$ \\
\hline Cylinder fracture & 0 & $0 \%$ & 0 & $0 \%$ & - \\
\hline Artificial gingiva fracture & 1 & $20 \%$ & 2 & $40 \%$ & .54 \\
\hline Abutment fracture & 0 & $0 \%$ & 0 & $0 \%$ & - \\
\hline Abutment screw loosening & 5 & $25 \%$ & 1 & $5 \%$ & $.049 *$ \\
\hline Prosthetic screw fracture & 2 & $10 \%$ & 2 & $10 \%$ & 1.00 \\
\hline Prosthetic screw loosening & 3 & $15 \%$ & 3 & $15 \%$ & 1.00 \\
\hline
\end{tabular}

\section{DISCUSSION}

The most common biological complication was increased pocket depth and marginal bone loss which was observed around $25 \%$ the posterior (tilted) implants. A similar observation was also noted in a recent study ${ }^{(15)}$ in which the authors found that participants with vertical bone loss of 3 $\mathrm{mm}$ was detected. The increased bone loss together with gingival inflammation and enlargement may be responsible for increase pocket depth. A similar observation was noted in anotherstudy ${ }^{(20)}$,in which the authors reported that ongoing bone resorption was reported in $50 \%$ of the participants and forms an alarming feature in the near future. They attributed the increased bone loss to the overloading forces of immediate lauding and surgery-related aspects which need to be investigated sufficiently.
The implant survival rate was $95 \%$ in each group. Similarly, Malo et al. (8) reported that, the success rate of all on four implants in the mandibular jaw was between $93.2 \%$ and $100 \%$ with 1 to 5 years of follow-up. In the current study, the failures occurred within 3 months after loading with provisional dentures. In agreement with this finding, a systematic review ${ }^{(21)}$ reported that most failures (74\%) happened after 6 months of implant installation and loading.

Twenty percent of implants in each group were associated with peri-implant mucositis and bleeding on probing. This could be attributed to the screw retained nature of the prosthesis which need complete removal by the prosthodontist in order to perform adequate cleaning around the implants. The lack of cleaning may lead to increased plaque 
accumulation, increased mucosal inflammation and bleeding on probing ${ }^{(7,22)}$.

PFM was associated with significant higher pocket depth and marginal bone loss than MAP. This could be attributed to the increased impact strength values of porcelain teeth compared to acrylic teeth which transfer more load to the implant during mastication. On the other hand the acrylic artificial teeth had a higher shock absorbability than porcelain teeth which reduce force transmission to the implants ${ }^{(23)}$ and could be responsible for reduced marginal bone loss in this group. It should be noted that, in this study the acrylic resin was finished to the metal at the buccal and lingual surface of the prosthesis and the tissue surface of the prosthesis was left as a polished metal with $1 \mathrm{~mm}$ space for cleaning purposes. This may help the patients wearing MAP for adequate cleansing and performing good oral hygiene compared to PFM prosthesis which need total removal to clean the prosthesis. The adequate cleaning the peri-implant tissues together with reduced marginal bone loss in the MAP may be responsible for reduced pocket depth in this group. The lack of difference in other biologic complications between groups suggested that both types of prosthesis are valid in terms of peri-implant tissue health. However, MAP may be advantageous than PFM regarding pocket depth and marginal bone loss.

With respect to provisional denture, the most common complication was prosthetic screw loosening (45\%) and denture fracture (40\%). In line with our findings, and in a systematic review, Patzelt et al. ${ }^{(21)}$ reported that majority of fractures happened in all-acrylic restoration without metal reinforcements and the prosthetic screw loosening. The increase incidence of denture fracture may be due to thinning of the acrylic resin denture base around the abutments during pickup of the temporary metal caps to the provisional denture. Another reason may be due to removal of denture flanges which contribute to weakening of the acrylic denture base. Although, the labial and buccal flanges only were removed and the lingual flanges were left to increase the rigidity of the prothesis, this did not prevent denture deformation and fracture under occlusal forces. Therefore, it becomes important to reinforce the denture before pick up procedure to prevent the provisional denture fracture during healing period. Therefore, it is advisable to make a metal reinforcement of the restoration to resist fracture, especially in subjects with parafunctional habits ${ }^{(21)}$. A third explanation may be due to patients switch from soft to hard diet after implant rehabilitation and immediate loading ${ }^{(7,24)}$. Similarly, the increased fracture of provisional restoration was reported recently by Malo et al. ${ }^{(15)}$ as the most common complication with All on four implant restoration $(18.3 \%)$. The authors also reported increased incidence of prosthetic screw loosening (15.9\%). Agliardi and colleagues (25) showed fractures of majority of acrylic restoration from 3 to 6 months, and Francetti and colleagues ${ }^{(7)}$ showed fracture of 7 acrylic restoration from 4-6 months of use. The increased incidence of screw loosening of provisional prosthesis was also reported in other studies ${ }^{(9,26,27)}$. The increased screw loosening may be due to increased occlusal forces by the patients when shifts from soft to hard food as a result of improved bite forces, muscle activity and masticatory efficiency secondary to implant rehabilitation ${ }^{(28)}$. In this study the treatment of this complication included retightening, controlling the occlusion and advising not to overload.

For definitive prosthesis, the most common complication was crown fracture and teeth wear in the MAP group. Also crown fracture and teeth wear/replacement were significantly higher in MAP than PFM. Similarly, McGlumphy ${ }^{(29)}$ found that the most frequent complication in MAP was the fracture of crowns (teeth) which was noted in 45.8 $\%$ of patients. The fractured teeth were replaced in the lab. All teeth fractures occurred in the anterior 
region next to lateral incisor and canine area. The artificial teeth separation and fracture may be due to insufficient space for the teeth due thick metal abutments in the anterior teeth and insufficient thickness of acrylic resin as increase acrylic resin in this area will result in lip bulging and affect esthetics. This may result in rapid separation of acrylic teeth especially under habitual biting on anterior teeth. The increased wear of acrylic resin teeth was in line with findings of Attard \& Zarb who reported teeth wear, and teeth fracture as the most complications with the MAP ${ }^{(30)}$. Also, McGlumphy ${ }^{(29)}$ reported that teeth renewal due to wear was the second frequent problem with MAP. Also, Priest et al..$^{(31)}$ reported that the replacement of denture teeth due to wear or fracture was the most common prosthetic complication of MAP. The increased wear of acrylic resin teeth in MAP may be due to improved bite force and reduced resistance of acrylic resin to wear. Therefore, reinforcement of acrylic resin teeth when using MAP may be recommended. Because of wear, all the teeth had to be replaced by the laboratory.

For both groups also prosthetic screw loosening of definitive prosthesis was the second common complication. This could be attributed to several factors. Firstly, the increased bite force caused by implant rehabilitation and improved masticatory efficiency transmit more occlusal forces to the prosthesis as mentioned before for provisional prosthesis which may loosen the screw. Secondly, the absolute passivity of the metal superstructures in both types of prosthesis seems nearly impossible which may contribute to screw loosening. In agreement with this observation, a misfit was noted in $80 \%$ of supra-structures ( $81 \%$ of restorations) ${ }^{(32)}$. Finally, the cantilevered portions of the frameworks in both types of prosthesis could be responsible for transmitting more load to the implants resulting in increased screw loosening ${ }^{(33)}$

The prosthetic screw loosening situations were resolved by retightening the prosthetic and abutment screws, controlling the occlusion, and advising the patient not to overload the prosthesis ${ }^{(9)}$.

In this study, abutment screw loosening was significantly higher in PFM than MAP. Similar to this observation, Maló et al. found $14.9 \%$ prosthesis screw loosening for PFM prosthesis ${ }^{(15)}$. In a recent report, McGlumphy et al. ${ }^{(29)}$ found $8.1 \%$ of retaining screws loosening for metal acrylic fixed full arch prosthesis. Most of these problems happened in the posterior implants. The increased screw loosening with PFM prosthesis compared to MAP may be attributed to the increased impact strength of porcelain teeth compared to acrylic teeth as stated previously ${ }^{(23)}$. On the other hand, the acrylic teeth have a shock absorption ability which reduce force transmission to the implants and reduce screw loosening.

\section{CONCLUSION}

Within the limitation of the current study regarding the small sample size it could be conclude that both porcelain fused to metal and metal acrylic fixed prosthesis could be used successfully for All on four implant rehabilitation of edentulous mandible after 3 years follow up period. However, MAP may be advantageous than PFM regarding biologic complications (increased pocket depth and marginal bon loss) and abutment screw loosening. On the other hand, PFM may be preferred than MAP in terms of crown fracture and teeth wear/ replacement.

\section{REFERENCES}

1. Weinstein R, Agliardi E, Fabbro MD, Romeo D, Francetti L. Immediate rehabilitation of the extremely atrophic mandible with fixed full-prosthesis supported by four implants. Clin Implant Dent Relat Res. 2012;14(3): 434-441.

2. Sadowsky SJ. The implant-supported prosthesis for the edentulous arch: design considerations. J Prosthet Dent. 1997;78(1):28-33. 
3. Malo P, Rangert B, Nobre M. "All-on-Four" immediatefunction concept with Branemark System implants for completely edentulous mandibles: a retrospective clinical study. Clin Implant Dent Relat Res. 2003;5 Suppl 1:2-9.

4. Malo P, Rangert B, Nobre M. All-on-4 immediate-function concept with Branemark System implants for completely edentulous maxillae: a 1-year retrospective clinical study. Clin Implant Dent Relat Res. 2005;7 Suppl 1:S88-94.

5. Krekmanov L. Placement of posterior mandibular and maxillary implants in patients with severe bone deficiency: a clinical report of procedure. Int $\mathrm{J}$ Oral Maxillofac Implants. 2000;15(5):722-730.

6. Pozzi A, Sannino G, Barlattani A. Minimally invasive treatment of the atrophic posterior maxilla: a proof-ofconcept prospective study with a follow-up of between 36 and 54 months. J Prosthet Dent. 2012;108(5):286-297.

7. Francetti L, Agliardi E, Testori T, Romeo D, Taschieri S, Del Fabbro M. Immediate rehabilitation of the mandible with fixed full prosthesis supported by axial and tilted implants: interim results of a single cohort prospective study. Clin Implant Dent Relat Res. 2008;10(4):255-263.

8. Malo P, de Araujo Nobre M, Lopes A. The use of computerguided flapless implant surgery and four implants placed in immediate function to support a fixed denture: preliminary results after a mean follow-up period of thirteen months. J Prosthet Dent. 2007;97(6 Suppl):S26-34.

9. Malo P, de Araujo Nobre M, Lopes A, Francischone C, Rigolizzo M. "All-on-4” immediate-function concept for completely edentulous maxillae: a clinical report on the medium (3 years) and long-term (5 years) outcomes. Clin Implant Dent Relat Res. 2012;14 Suppl 1:e139-150.

10. Tallarico M, Canullo L, Pisano M, Peñarrocha-Oltra D, Peñarrocha-Diago M, Meloni SM. An up to 7-Year Retrospective Analysis of Biologic and Technical Complication With the All-on-4 Concept. J Oral Implantol. 2016;42(3):265-271.

11. Zarb GA, Albrektsson T. Tissue-integrated prosthesis: osseointegration in clinical dentistry: Quintessence Pub Co; 1985.

12. Maló P, Rangert B, Nobre M. All-on-4 immediate-function concept with Brånemark System implants for completely edentulous maxillae: a 1-year retrospective clinical study. Clin Implant Dent Relat Res. 2005; 7 Suppl 1:S88-S94.

13. Malo P, de Araujo Nobre M, Rangert B. Implants placed in immediate function in periodontally compromised sites: a five-year retrospective and one-year prospective study. J Prosthet Dent. 2007;97(6 Suppl):S86-95.

14. Agliardi E, Panigatti S, Clerico M, Villa C, Malo P. Immediate rehabilitation of the edentulous jaws with full fixed prosthesis supported by four implants: interim results of a single cohort prospective study. Clin Oral Implants Res. 2010;21(5):459-465.

15. Maló P, de Araújo Nobre M, Lopes A, Ferro A, Botto J. The All-on-4 treatment concept for the rehabilitation of the completely edentulous mandible: A longitudinal study with 10 to 18 years of follow-up. Clin Implant Dent Relat Res. 2019. doi: 10.1111/cid.12769. [Epub ahead of print]

16. Cawood JI, Howell RA. A classification of the edentulous jaws. Int J Oral Maxillofac Surg. 1988;17(4):232-236.

17. Malo Bo R, Nobre M. Concept with Brlaanemark System Itextregistered Implants for Completely Edentulous Mandibles : A Retrospective Clinical Study. Implant dentistry. 2003:2-9.

18. Sannino G, Bollero P, Barlattani A, Gherlone E. A Retrospective 2-Year Clinical Study of Immediate Prosthetic Rehabilitation of Edentulous Jaws with Four Implants and Prefabricated Bars. J Prosthodont. 2017;26(5):387-394.

19. Galindo DF, Butura CC. Immediately loaded mandibular fixed implant prosthesis using the all-on-four protocol: a report of 183 consecutively treated patients with 1 year of function in definitive prosthesis. The International journal of oral \& maxillofacial implants. 2012;27(3):628-633.

20. Browaeys H, Dierens M, Ruyffelaert C, Matthijs C, De Bruyn H, Vandeweghe S. Ongoing Crestal Bone Loss around Implants Subjected to Computer-Guided Flapless Surgery and Immediate Loading Using the All-on-4(R) Concept. Clin Implant Dent Relat Res. 2015;17(5):831843.

21. Patzelt SB, Bahat O, Reynolds MA, Strub JR. The all-onfour treatment concept: a systematic review. Clin Implant Dent Relat Res. 2014;16(6):836-855.

22. Francetti L, Romeo D, Corbella S, Taschieri S, Del Fabbro M. Bone level changes around axial and tilted implants in full-arch fixed immediate restorations. Interim results of a prospective study. Clin Implant Dent Relat Res. 2012;14(5):646-654.

23. Kawano F, Ohguri T, Ichikawa T, Mizuno I, Hasegawa A. Shock absorbability and hardness of commercially 
available denture teeth. Int J Prosthodont. 2002; 15(3): 243-247.

24. Agliardi E, Clerico M, Ciancio P, Massironi D. Immediate loading of full-arch fixed prosthesis supported by axial and tilted implants for the treatment of edentulous atrophic mandibles. Quintessence Int. 2010;41(4):285-293.

25. Agliardi E, Clericò M, Ciancio P, Massironi D. Immediate loading of full-arch fixed prosthesis supported by axial and tilted implants for the treatment of edentulous atrophic mandibles. Quintessence Int. 2010;41(4).

26. Malo P, de Araujo Nobre M, Lopes A, Moss SM, Molina GJ. A longitudinal study of the survival of All-on-4 implants in the mandible with up to 10 years of follow-up. $\mathrm{J}$ Am Dent Assoc. 2011;142(3):310-320.

27. Crespi R, Vinci R, Cappare P, Romanos GE, Gherlone E. A clinical study of edentulous patients rehabilitated according to the "all on four" immediate function protocol. Int $\mathrm{J}$ Oral Maxillofac Implants. 2012;27(2):428-434.

28. Elsyad MA, Khairallah AS. Chewing efficiency and maximum bite force with different attachment systems of implant overdentures: a crossover study. Clin Oral Implants Res. 2017; 28(6):677-682.
29. McGlumphy EA, Hashemzadeh S, Yilmaz B, Purcell BA, Leach D, Larsen PE. Treatment of edentulous mandible with metal-resin fixed complete dentures: A 15- to 20-year retrospective study. Clin Oral Implants Res. 2019. doi: 10.1111/clr.13488. [Epub ahead of print]

30. Attard NJ, Zarb GA. Long-term treatment outcomes in edentulous patients with implant-fixed prosthesis: the Toronto study. Int J Prosthodont. 2004;17(4):417-424.

31. Priest G, Smith J, Wilson MG. Implant survival and prosthetic complications of mandibular metal-acrylic resin implant complete fixed dental prosthesis. J Prosthet Dent. 2014;111(6):466-475.

32. Landázuri-Del Barrio RA, Cosyn J, De Paula WN, De Bruyn H, Marcantonio E. A prospective study on implants installed with flapless-guided surgery using the all-onfour concept in the mandible. Clin Oral Implants Res. 2013;24(4):428-433.

33. Hemmings KW, Schmitt A, Zarb GA. Complications and maintenance requirements for fixed prosthesis and overdentures in the edentulous mandible: a 5-year report. International Journal of Oral \& Maxillofacial Implants. 1994; 9(2). 